\title{
Thyroid imaging study in children with suspected thyroid dysgenesis
}

\author{
Sangwoo Chun', \\ Young Seok Lee', \\ Jeesuk Yu ${ }^{1}$
}

'Department of Pediatrics, Dankook University Hospital, Dankook University College of Medicine, Cheonan, Korea ${ }^{2}$ Department of Radiology, Dankook University Hospital, Dankook University College of Medicine, Cheonan, Korea
Received: 13 June, 2020

Revised: 16 August, 2020

Accepted: 27 August, 2020

\section{Address for correspondence:}

JeesukYu

Department of Pediatrics, Dankook University Hospital, Dankook University College of Medicine, 201 Manghyang-ro, Dongnam-gu, Cheonan 31116, Korea

Email:dryujs@dankook.ac.kr

https://orcid.org/0000-0003-00202000
Purpose: Thyroid dysgenesis is one of the most common causes of permanent congenital hypothyroidism. Thyroid ultrasonography or scan is used to detect thyroid dysgenesis. We analyzed the sensitivity and specificity of thyroid ultrasonography and scan in diagnosing thyroid dysgenesis to determine the clinical utility of each thyroid imaging method.

Methods: Sixty-one patients younger than 7 years of age were investigated via thyroid scan. Nineteen patients who were initially interpreted as having thyroid dysgenesis, such as ectopia, hemiagenesis, or aplasia, by thyroid scan were included in the study. Clinical characteristics and findings of a thyroid imaging study were reviewed.

Results: Initially, thyroid scan results were interpreted as ectopia $(n=9)$, hemiagenesis $(n=1)$, and nonvisualization $(n=9)$. In contrast, the results of thyroid ultrasonography were normal thyroid gland $(n=5)$, ectopia $(n=6)$, and hypoplasia $(n=8)$. After reviewing the results of both studies, final imaging diagnoses were as follows: normal thyroid gland $(n=5)$, hemiagenesis $(n=1)$, ectopia $(n=9)$ including 2 dual ectopy, hypoplasia $(n=3)$, and aplasia $(n=1)$. Thyroid ultrasonography showed higher sensitivity and specificity in detecting presence of normal thyroid gland. Thyroid scan was better to detect ectopia. Among 8 patients who were initially interpreted as having hypoplasia by ultrasonography, 4 were confirmed as ectopia and one as aplasia.

Conclusion: This study showed that thyroid ultrasonography is useful as the firstline imaging study to detect normal-sized eutopic thyroid gland. Thyroid scan should be performed to investigate the presence of ectopia if hypoplasia or aplasia is suspected by ultrasonography.

Keywords: Thyroid dysgenesis, Ultrasonography, Scan

\section{Highlights}

- Thyroid ultrasonography showed higher sensitivity and specificity in detecting presence of normal thyroid gland. Thyroid ultrasonography is useful as the first-line imaging study to detect normal-sized eutopic thyroid gland.

- Thyroid scan was better to detect ectopia. Thyroid scan should be performed to investigate the presence of ectopia if hypoplasia or aplasia is suspected by ultrasonography.

\section{Introduction}

Thyroid hormone is important for normal growth and development in children. ${ }^{1-3)}$ Congenital hypothyroidism was the leading cause of intellectual impairment in neonates if not treated early. After introduction of universal neonatal screening test (NST), congenital hypothyroidism can be identified. The incidence of congenital hypothyroidism increased 
from 1 in 4,000 to 1 in 2,000 over the last 20 years because of the performance of NST and establishment of lower thyroidstimulating hormone (TSH) thresholds, leading to greater detection of milder congenital hypothyroidism. ${ }^{3,4)}$

The fetal thyroid gland arises from an outpouching of the foregut at the base of the tongue. The cells of the thyroid anlage and the ultimobranchial bodies migrate from the original sites and merge in the definitive thyroid gland. ${ }^{5}$

Thyroid dysgenesis is one of the most common causes of permanent congenital hypothyroidism, accounting for $85 \%$ of primary congenital hypothyroidism. ${ }^{5}$ Thyroid dysgenesis presents in 3 major forms: ectopia, hypoplasia, and aplasia. Thyroid dysgenesis can be detected by thyroid imaging, such as thyroid ultrasonography and thyroid scan. Thyroid ectopia is defined as functional thyroid tissue located anywhere other than the normal anatomic location of the thyroid gland, and the prevalence of thyroid ectopia is reported as 1 in 100,000 to 300,000 in the population. ${ }^{6}$. Dual ectopia is possible but is very rare. $^{7-10)}$ Thyroid dysgenesis has been considered to be sporadic, although recent papers reported that $2 \%-12 \%$ of thyroid dysgenesis cases are familial. ${ }^{1,12)}$

Thyroid imaging is valuable if thyroid dysfunction was detected in a neonate because it can be helpful to establish a long-term therapeutic plan, as well as for early detection of an ectopic thyroid gland. ${ }^{2,13)}$ Ectopic thyroid might lead to cretinism or a large goiter, which can cause life-threatening compression of surrounding structures if diagnosis and therapy are delayed. ${ }^{14-16)}$

In this study, we reviewed the clinical characteristics of thyroid dysgenesis by type and analyzed the sensitivity and specificity of thyroid scan and ultrasonography in diagnosing thyroid dysgenesis to investigate clinical utility of each method for diagnosis of thyroid dysgenesis.

\section{Materials and methods}

\section{Study participants}

This study was performed at the department of pediatric endocrinology in a single tertiary care hospital in Cheonan, South Korea. All study participants were referred for suspected thyroid dysfunction. A total of 61 patients younger than 7 years was evaluated by thyroid scan due to abnormal result of NST or thyroid function test (TFT), palpable neck mass, or other suggestive symptoms of hypothyroidism, such as constipation or developmental delay, between 2002 and 2017. After reviewing the results of thyroid scan, 42 individuals who revealed normally positioned thyroid gland were excluded from the study. A total of 19 individuals was included in the study (Fig. $1)$.

\section{Thyroid imaging study using thyroid scan and thyroid ultrasonography}

The thyroid scan finding was reviewed along with those of thyroid ultrasonography. Thyroid scan was performed after intravenous injection of $1-2 \mathrm{mCi}$ of $99 \mathrm{mTc}$ by gamma cameras (GE Hawkeye 4, GE Healthcare, Milwaukee, WI, USA or Siemens symbia E, Siemens Medical Solutions, Malvern, PA, USA) equipped with a pin-hole collimator. The anterior image was obtained in the supine position with the neck extended by a pillow under the shoulder. If necessary, a lateral image was obtained. The presence, absence, shape, and location of areas of ${ }^{99 m} \mathrm{TcO} 4$ uptake were recorded. Thyroid ultrasonography was performed by gray-scale US with a $12-5 \mathrm{MHz}$ linear probe (Philips IU22, EPIQ 7, Bothell, WA, USA) and prewarmed gel. The participants were examined in the supine position with an extended neck. Ultrasonography evaluated the presence of a thyroid gland and isthmus at normal locations, as well as the volume of each lateral lobe as calculated by the formula: depth $\times$ length $\times$ width $\times \pi / 6 .{ }^{17)}$ Total thyroid volume was obtained by summing the volumes of all lobes. The diagnosis of hypoplasia was based on values suggested by several reports. ${ }^{17-19)}$

\section{Measurement of TFT}

The serum levels of T3, free T4, TSH, and thyroglobulin were analyzed by electrochemiluminescence immunoassay (Cobas E601 HITACHI Immunoassay Analyzers, Hitachi High Technology Co., Tokyo, Japan).

\section{Statistical analysis}

Statistical analysis was performed using R ver. 3.5.3 (R Foundation for Statistical Computing, Vienna, Austria). Sex; age at first visit; age at most recent visit; follow-up duration; initial presentation; accompanying clinical condition; family history; initial values of total T3, free T4, TSH, and thyroglobulin; initial dose of medication; and z-scores of recent height and weight were analyzed. Comparison of each variable among 5 groups

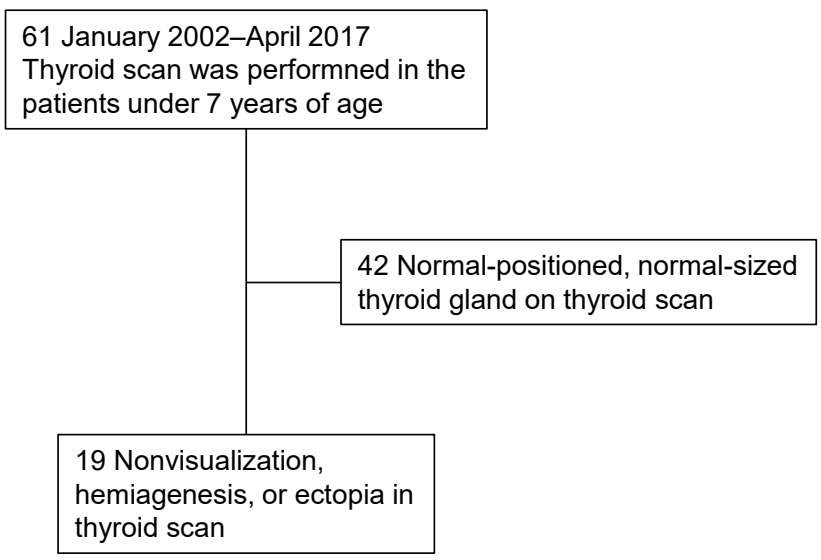

Fig. 1. Flow diagram of the study. A total of 19 participants was included in the study after excluding 42 individuals who revealed normal-positioned, normalsized thyroid gland on thyroid scan. 
classified by final diagnosis was performed with Kruskal-Wallis test. Diagnostic utility of thyroid imaging study in congenital hypothyroidism was evaluated by calculation of sensitivity, specificity, positive predictive value (PPV), negative predictive value (NPV), and accuracy of the study results. Sensitivity, specificity, and accuracy between thyroid ultrasonography and thyroid scan were compared using McNemar test. For testing the statistical difference between predictive values, a generalized score statistic method was used.

\section{Results}

\section{Study participants}

A total of 19 children showing ectopic thyroid, hemiagenesis, or no detectable thyroid tissue on thyroid scan was included in the study. These comprised 5 males and 14 females. The mean age of the patients at first visit was $5.26 \pm 9.65$ months (range, 0.36-33.83 months). Initial presentation consisted of abnormal NST $(n=16)$, developmental delay and low T4 $(n=1)$, mass on

Table 1. Baseline characteristics of 19 patients

\begin{tabular}{lc}
\hline Characteristic & Value \\
\hline Sex & $5(26.3)$ \\
Male & $14(73.7)$ \\
Female & $5.26 \pm 9.65(0.36-33.83)$ \\
Age at first visit (mo) & $6.86 \pm 3.95(0.82-15.10)$ \\
Age at recent visit (yr) & $6.54 \pm 4.26(0.46-15.60)$ \\
Follow-up duration (yr) & $16(84.2)$ \\
Initial presentations & $1(5.3)$ \\
Abnormal NST & $1(5.3)$ \\
Developmental delay and low T4 & $1(5.3)$ \\
Tongue base mass & $4(21.1)$ \\
Constipation & $1(5.3)$ \\
Accompanying clinical condition & \\
Prematurity (28 +3 -35 wk) & \\
Schizencephaly & \\
\hline Values are presented as mean \pm standard deviation (range) or \\
number (\%).
\end{tabular}

tongue base $(n=1)$, or constipation $(n=1)$ (Table 1$)$.

\section{Results of thyroid imaging study}

Initial interpretations of the thyroid scan were ectopia $(n=9 ; 6$ lingual or sublingual, 1 anterior neck, 2 dual ectopia), hemiagenesis $(n=1)$, and nonvisualization $(n=9)$. In contrast, initial readings of thyroid ultrasonography were ectopia $(n=6)$, hypoplasia $(n=8)$, and normal $(n=5)$. The ultrasonographic images were reviewed along with the results of thyroid scan and clinical features. The final diagnosis obtained based on clinical information, as well as review and reassessment of the results of thyroid scan and thyroid ultrasonography by experts was as follows: ectopia $(n=9,47.4 \%)$, hemiagenesis $(\mathrm{n}=1,5.3 \%)$, hypoplasia $(\mathrm{n}=3,15.8 \%)$, aplasia $(\mathrm{n}=1,5.3 \%)$, and normal $(n=5,26.3 \%)$ (Fig. 2, Table 2). Some changes occurred in the interpretations of thyroid sonography. Among 6 participants who were initially interpreted as having ectopia by thyroid ultrasonography, 1 was confirmed as having hemiagenesis. Among 8 participants who were initially interpreted as hypoplasia by ultrasonography, 4 were confirmed as ectopia and 1 as aplasia. Some changes also occurred in the interpretations of thyroid scan. Among 9 individuals who were initially interpreted as nonvisualization of the thyroid gland by thyroid scan, 5 were confirmed as having a normal thyroid gland, and 3 were confirmed as having hypoplasia by thyroid ultrasonography (Fig. 2). In the study, the most common thyroid dysgenesis was ectopia ( 9 of 14, 64.3\%). Dual ectopia and hemiagenesis also were found, and those images are presented in Fig. 3.

Table 2. Final diagnosis based on the results of both thyroid scan and thyroid ultrasonography

\begin{tabular}{lc}
\hline Final diagnosis & No. (\%) \\
\hline Ectopia & $9(47.4)$ \\
Hemiagenesis & $1(5.3)$ \\
Hypoplasia & $3(15.8)$ \\
Aplasia & $1(5.3)$ \\
Normal thyroid gland & $5(26.3)$ \\
\hline
\end{tabular}

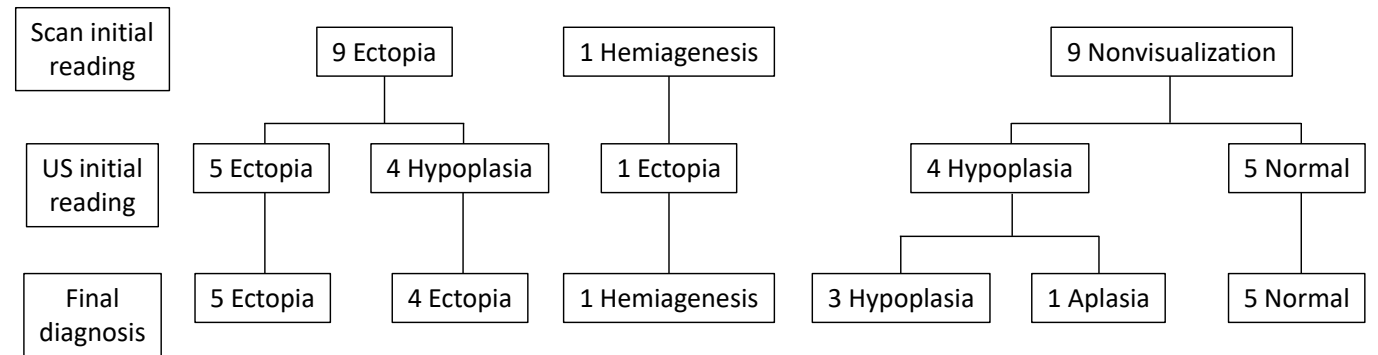

Fig. 2. Grouping of the patients according to the final diagnosis based on the results of thyroid scan and ultrasonography (US). Initial interpretations of thyroid scan and thyroid ultrasonography were changed as follows: ectopia $(n=9)$, hemiagenesis $(n=1)$, hypoplasia $(n=3)$, aplasia $(n=1)$, and normal $(n=5)$. 


\section{Clinical and laboratory findings}

Clinical and laboratory features of the patients were reviewed according to type of thyroid dysgenesis. More girls were observed with ectopia, hemiagenesis, hypoplasia, and aplasia, but there was no statistically significant difference among subgroups. Age at first visit, clinical features of initial presentation, initial result of TFT, recent $z$-scores of height and weight, and medication duration showed no statistically significant differences among subgroups (Table 3). Initial TSH level was only mildly elevated in some patients.

\section{Diagnostic utility of thyroid imaging study in congenital hypothyroidism}

Sensitivity, specificity, PPV, NPV, and accuracy of initial

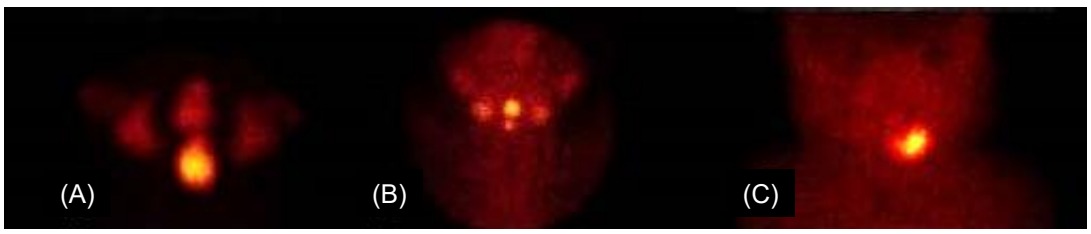

Fig. 3. There were 2 patients with dual ectopy (A, B) and 1 patient with hemiagenesis (C). Dual ectopia was found at the level of lingual/sublingual and submandibular areas (A) and sublingual areas (B), respectively.

Table 3. Clinical and demographic features of the subjects according to the final diagnosis

\begin{tabular}{|c|c|c|c|c|c|c|}
\hline Variable & Ectopia $(n=9)$ & Hemiagenesis $(n=1)$ & Hypoplasia $(n=3)$ & Aplasia $(n=1)$ & Normal thyroid gland $(n=5)$ & $P$-value \\
\hline Sex, male:female & $1: 8$ & $0: 1$ & $1: 2$ & $0: 1$ & $3: 2$ & 0.34 \\
\hline Age at first visit (mo) & $\begin{array}{c}7.69 \pm 13.76 \\
(0.36-33.83)\end{array}$ & 0.53 & $\begin{array}{c}4.10 \pm 2.19 \\
(1.81-6.18)\end{array}$ & 0.46 & $\begin{array}{l}3.50 \pm 2.87 \\
(0.72-6.9)\end{array}$ & 0.39 \\
\hline Age at recent visit (yr) & $\begin{array}{c}7.67 \pm 2.75 \\
(3.11-11.24)\end{array}$ & 10.21 & $\begin{array}{c}0.92 \pm 0.15 \\
(0.82-1.09)\end{array}$ & 4.56 & $\begin{array}{c}8.75 \pm 4.30 \\
(3.51-15.10)\end{array}$ & 0.07 \\
\hline Follow-up duration (yr) & $\begin{array}{c}7.13 \pm 3.37 \\
(0.62-11.33)\end{array}$ & 10.31 & $\begin{array}{c}0.59 \pm 0.13 \\
(0.46-0.72)\end{array}$ & 4.59 & $\begin{array}{c}8.69 \pm 4.60 \\
(3.41-15.60)\end{array}$ & 0.09 \\
\hline \multicolumn{7}{|l|}{ Initial presentations } \\
\hline Abnormal NST & $8(88.9)$ & $1(100)$ & $2(66.7)$ & $1(100)$ & $4(80)$ & 0.88 \\
\hline Tongue base mass & $1(11.1)$ & $0(0)$ & $0(0)$ & $0(0)$ & $0(0)$ & 0.89 \\
\hline Developmental delay & $0(0)$ & $0(0)$ & $1(33.3)$ & $0(0)$ & $0(0)$ & 0.25 \\
\hline Constipation & $0(0)$ & $0(0)$ & $0(0)$ & $0(0)$ & $1(20)$ & 0.59 \\
\hline \multicolumn{7}{|l|}{ Accompanied clinical conditions } \\
\hline Prematurity & $1(11.1)$ & $0(0)$ & $1(33.3)$ & $0(0)$ & $2(40)$ & 0.68 \\
\hline Schizencephaly & $0(0)$ & $0(0)$ & $1(33.3)$ & $0(0)$ & $0(0)$ & 0.25 \\
\hline Developmental delay & $0(0)$ & $0(0)$ & $1(33.3)$ & $0(0)$ & $1(20)$ & 0.52 \\
\hline \multicolumn{7}{|l|}{ Family history of thyroid disease } \\
\hline Thyroid cancer & $1(11.1)$ & $0(0)$ & $0(0)$ & $0(0)$ & $0(0)$ & 0.89 \\
\hline Congenital hypothyroidism & $0(0)$ & $0(0)$ & $1(33.3)$ & $0(0)$ & $0(0)$ & 0.25 \\
\hline \multicolumn{7}{|l|}{ Initial thyroid function test } \\
\hline Total T3 (ng/dL) & $\begin{array}{c}114.4 \pm 55.8 \\
(37.0-195.8)\end{array}$ & 113.7 & $\begin{array}{c}82.6 \pm 37.8 \\
(43.7-119.1)\end{array}$ & 36.4 & $\begin{array}{c}132.8 \pm 93.1 \\
(14.8-240.2)\end{array}$ & 0.45 \\
\hline Free T4 (ng/dL) & $\begin{array}{c}0.91 \pm 0.58 \\
(0.17-1.62)\end{array}$ & 0.42 & $\begin{array}{c}0.65 \pm 0.34 \\
(0.35-1.02)\end{array}$ & 0.09 & $\begin{array}{c}0.75 \pm 0.29 \\
(0.33-1.08)\end{array}$ & 0.46 \\
\hline TSH $(\mu l \mathrm{U} / \mathrm{mL})$ & $\begin{array}{l}193.4 \pm 348.1 \\
(9.18-1,000)\end{array}$ & 64.4 & $\begin{array}{c}18.32 \pm 25.8 \\
(1.57-48.00)\end{array}$ & 100 & $\begin{array}{l}16.3 \pm 16.7 \\
(0.7-41.4)\end{array}$ & 0.20 \\
\hline Thyroglobulin (ng/mL) & $\begin{array}{c}302.2 \pm 251.4 \\
(16.35-696.8)\end{array}$ & 15.5 & $\begin{array}{l}26.5 \pm 26.8 \\
(7.6-45.4)\end{array}$ & 5.12 & $\begin{array}{l}18.5 \pm 12.0 \\
(9.1-36.7)\end{array}$ & 0.77 \\
\hline \multicolumn{7}{|l|}{ Recent follow-up } \\
\hline Height z-score & $\begin{array}{c}0.34 \pm 0.80 \\
(-0.62 \text { to } 2.01)\end{array}$ & -0.25 & $\begin{array}{c}-2.03 \pm 2.75 \\
(-4.93 \text { to } 0.55)\end{array}$ & 0.13 & $\begin{array}{c}-0.32 \pm 0.97 \\
(-1.31 \text { to } 1.16)\end{array}$ & 0.45 \\
\hline Weight z-score & $\begin{array}{c}0.55 \pm 1.17 \\
\text { (-1.07 to } 2.67)\end{array}$ & 0.93 & $\begin{array}{c}-2.31 \pm 1.95 \\
(-3.85 \text { to }-0.11)\end{array}$ & 0.7 & $\begin{array}{l}-0.59 \pm 1.28 \\
(-2.3 \text { to } 1.3)\end{array}$ & 0.14 \\
\hline Initial dose of Medication ( $\mu \mathrm{g} /$ day) & $37.2 \pm 7.7(25-50)$ & 40 & $30 \pm 26.5(0-50)$ & 33 & $34.0 \pm 8.9(20-40)$ & 0.93 \\
\hline
\end{tabular}

Values are presented as mean \pm standard deviation (range) or number (\%).

NST, neonatal screening test; TSH, thyroid-stimulating hormone. 
reading of the thyroid scan and ultrasonography were analyzed to determine their diagnostic utility in evaluation of thyroid dysgenesis. In detecting the presence of normal thyroid gland, thyroid ultrasonography showed higher values in sensitivity, PPV, NPV, and accuracy than thyroid scan (Table 4), although statistical significance was only found for NPV $(P=0.009)$. In diagnosis of ectopia, thyroid scan was superior to ultrasonography in NPV $(P=0.017)$. In detecting hypoplasia, thyroid ultrasonography showed a higher sensitivity than thyroid scan, although statistical significance was not identified by McNemar test. In diagnosing aplasia, thyroid ultrasonography showed better specificity $(P=0.013)$ and accuracy $(P=0.046)$ than thyroid scan.

\section{Discussion}

Management of congenital hypothyroidism has focused on early identification and treatment to maintain the euthyroid state, especially in the first few years of critical brain development. ${ }^{1,2)}$ Some clinicians do not recommend routine thyroid imaging when starting therapy, because the imaging result does not usually change the treatment plan of congenital hypothyroidism. However, early determination of the exact cause of congenital hypothyroidism can provide important information for genetic counseling and be useful to understand the need for lifelong therapy. ${ }^{2,13}$

This study investigated the diagnostic values of thyroid imaging study in children with suspected thyroid dysgenesis. Average age at thyroid scan and thyroid ultrasonography was $0.99 \pm 1.31$ years and $0.73 \pm 0.98$ years, respectively. We confirmed that thyroid ultrasonography is better as an initial evaluation of thyroid gland to find a normally positioned thyroid gland.

Table 4. Comparison of sensitivity, specificity, PPV, and NPV of initial readings of thyroid scan and thyroid ultrasonography based on the final diagnosis

\begin{tabular}{|c|c|c|c|c|c|}
\hline Variable & $\begin{array}{c}\text { Sensitivity } \\
(\%)\end{array}$ & $\begin{array}{c}\text { Specificity } \\
(\%)\end{array}$ & $\begin{array}{l}\text { PPV } \\
(\%)\end{array}$ & $\begin{array}{l}\text { NPV } \\
(\%)\end{array}$ & $\begin{array}{c}\text { Accuracy } \\
(\%)\end{array}$ \\
\hline \multicolumn{6}{|l|}{ Scan initial reading } \\
\hline Ectopia $(n=9)$ & 100 & 100 & 100 & 100 & 100 \\
\hline Hemiagenesis $(n=1)$ & 100 & 100 & 100 & 100 & 100 \\
\hline Hypoplasia (n=3) & 0 & 100 & NA & 84.2 & 84.2 \\
\hline Aplasia $(n=1)$ & 100 & 55.6 & 11.1 & 100 & 57.9 \\
\hline $\begin{array}{l}\text { Normal thyroid gland } \\
(\mathrm{n}=5)\end{array}$ & 0 & 100 & NA & 73.7 & 73.7 \\
\hline \multicolumn{6}{|l|}{ US initial reading } \\
\hline Ectopia $(n=9)$ & 55.6 & 90 & 83.3 & 69.2 & 73.7 \\
\hline Hemiagenesis $(n=1)$ & 0 & 100 & NA & 94.7 & 94.7 \\
\hline Hypoplasia ( $n=3$ ) & 100 & 68.8 & 37.5 & 100 & 73.7 \\
\hline Aplasia $(n=1)$ & 0 & 100 & NA & 94.7 & 94.7 \\
\hline $\begin{array}{l}\text { Normal thyroid gland } \\
(n=5)\end{array}$ & 100 & 100 & 100 & 100 & 100 \\
\hline \multicolumn{6}{|c|}{$\begin{array}{l}\text { PPV, positive predictive value; NPV, negative predictive value; NA, } \\
\text { not available; US, ultrasongraphy. } \\
\text { Accuracy=true positive+true negative/(true positive+true } \\
\text { negative+false negative+false positive). }\end{array}$} \\
\hline
\end{tabular}

We also found that it is necessary to perform a thyroid scan to confirm the presence of ectopia when hypoplasia or aplasia is suspected by thyroid ultrasonography.

Thyroid ultrasonography and scan have different advantages and disadvantages in evaluation of the thyroid gland ${ }^{20-23)}$ Thyroid ultrasonography is radiation free and does not require sedation. Moreover, it is valid for evaluation of normally positioned thyroid tissue. ${ }^{24)}$ However, thyroid ultrasonography requires expertise to successfully execute. Thyroid scan is a very useful imaging study to identify the existence and location of thyroid tissue. ${ }^{25)}$ However, estimation of exact size and morphology of thyroid gland are difficult by thyroid scan, and the results can be obscured by prior medication of thyroid hormone, iodine-containing agents, or the presence of TSH receptor blocking antibody.

In this study, some final diagnoses were changed to ectopia by thyroid scan when thyroid hypoplasia was suspected by thyroid ultrasonography ( 4 of $8,50 \%$ ). Five of 8 patients who were suspected as having hypoplasia by ultrasonography were confirmed as ectopia $(n=4)$ or aplasia $(n=1)$. During reevaluation of the thyroid ultrasonography images, hyperechoic fat tissues located at normal thyroid area were interpreted as thyroid tissue by thyroid ultrasonography. A similar result was reported by Bubuteishvili et al. ${ }^{26)}$ Karakoc-Aydiner et al. ${ }^{27)}$ and suggested the possibility of remnants of ultimobranchial bodies.

Ectopic thyroid is a well-known cause of congenital hypothyroidism. Dual ectopia can exist but is very rare. ${ }^{7-10)}$ In this study, there were 2 patients with dual ectopia. The ages at diagnosis of dual ectopia were 2 years 6 months and 2 years 9 months, respectively, and both were females. One patient visited our department for an incidentally noted mass on the tongue base, and the other patient visited for follow-up of an abnormal NST result. Neither patient was using thyroid hormone medication before visiting. The levels of free T4 and TSH were $1.62 \mathrm{ng} /$ $\mathrm{dL}$ and $9.18 \mathrm{mIU} / \mathrm{L}$ in the first case and $1.03 \mathrm{ng} / \mathrm{dL}$ and 13.04 $\mathrm{mIU} / \mathrm{L}$ in the second, respectively. Both cases were diagnosed as dual ectopia by thyroid scan and started thyroid hormone medication.

In this study, normal thyroid gland could not be detected by thyroid scan in some situations. There are many causes of nonvisualization of thyroid gland by scan such as prematurity, prior medication of thyroid hormone, congenital hypothyroidism with TSH receptor blocking antibody, or central type of congenital hypothyroidism in addition to thyroid aplasia. Clinical information and TFT results, as well as thyroid ultrasonography, should be reviewed in diagnosing thyroid aplasia. In this study, 5 participants who were confirmed as having a normal thyroid gland showed nonvisualization by thyroid scan. All showed a normal range of TSH level at the time of thyroid scan (TSH: $1.15 \pm 0.75$ [0.47-2.38] mIU/L). Among 5 patients, 4 started thyroid hormone medication before thyroid scan and 1 was a premature baby (gestational age $30^{+2}$ weeks) with normal TSH level (T3 $82.1 \mathrm{ng} / \mathrm{dL}$, free T4 $0.66 \mathrm{ng} / \mathrm{dL}$, TSH $2.38 \mathrm{mIU} / \mathrm{L}$ ). Three participants were confirmed as having hypoplasia by thyroid ultrasonography, although the thyroid 
did not reveal uptake by thyroid scan. Among 3 participants, 1 was a premature baby (gestational age $28^{+3}$ weeks) with normal TSH level (T3, $120.9 \mathrm{ng} / \mathrm{dL}$; free T4, $0.76 \mathrm{ng} / \mathrm{dL}$; TSH, $3.93 \mathrm{mIU} /$ L), 1 had central congenital hypothyroidism associated with schizencephaly (TSH, $0.03 \mathrm{mIU} / \mathrm{mL}$ ), and 1 had $\mathrm{TSH}$ receptor antibody. It is important to remember that nonvisualization by thyroid scan should not be concluded as aplasia without investigation by thyroid ultrasonography.

This study showed that thyroid ultrasonography is a better tool to detect normally positioned thyroid gland, implying that thyroid ultrasonography is useful as a first-line imaging study to detect normal thyroid gland. Thyroid scan is very useful in diagnosing ectopia and should be performed to investigate the presence of ectopia if hypoplasia or aplasia is suspected by thyroid ultrasonography. Both thyroid scan and ultrasonography are recommended in diagnosing aplasia or ectopia.

This study has some limitations, including a small study population and lack of comparison using definite thyroid volume among study participants. However, this study presented various detailed clinical information about congenital hypothyroidism, including dual ectopic patients, and emphasized the importance of thyroid imaging study in congenital hypothyroidism. We confirmed that thyroid ultrasonography is better as the initial evaluation to determine the normally positioned thyroid gland and found that it is necessary to perform thyroid scan to investigate the presence of ectopia when hypoplasia or aplasia is suspected by thyroid ultrasonography.

In conclusion, this study showed that thyroid ultrasonography is useful as the first-line imaging study to detect normal thyroid gland. Thyroid scan was required to investigate the presence of ectopia if hypoplasia or aplasia was suspected by ultrasonography. Both thyroid scan and ultrasonography are recommended in diagnosing aplasia or ectopia.

\section{Ethical statement}

The study was approved by the Institutional Review Board of Dankook University Hospital (approval number: DKUH 201804-022). The requirement for informed consent was waived due to the retrospective nature of the study.

\section{Conflict of interest}

No potential conflict of interest relevant to this article was reported.

\section{Acknowledgments}

We thank Seok Gun Park, MD, PhD, for interpretation of thyroid scans.

\section{References}

1. LaFranchi SH. Approach to the diagnosis and treatment of neonatal hypothyroidism. J Clin Endocrinol Metab 2011;96:2959-67.

2. Léger J, Olivieri A, Donaldson M, Torresani T, Krude $H$, van Vliet $G$, et al. European society for paediatric endocrinology consensus guidelines on screening, diagnosis, and management of congenital hypothyroidism. J Clin Endocrinol Metab. 2014;99:363-84.

3. Cherella CE, Wassner AJ. Congenital hypothyroidism: insights into pathogenesis and treatment. Int J Pediatr Endocrinol 2017;2017:11.

4. Hinton CF, Harris KB, Borgfeld L, Drummond-Borg M, Eaton R, Lorey F, et al. Trends in incidence rates of congenital hypothyroidism related to select demographic factors: data From the United States, California, Massachusetts, New York, and Texas. Pediatrics 2010;125 Suppl 2:S37-47.

5. De Felice M, Di Lauro R. Thyroid development and its disorders: genetics and molecular mechanisms. Endocr Rev 2004;25:722-46.

6. Szczepanek-Parulska E, Hernik A, Ruchala M. Thyroid ectopy - diagnostic and therapeutic challenges before and in the era of TSH neonatal screening. Endokrynol Pol 2017;68:708-21.

7. Sood A, Sood V, Sharma DR, Seam RK, Kumar R. Thyroid scintigraphy in detecting dual ectopic thyroid: a review. Eur J Nucl Med Mol Imaging 2008;35:843-6.

8. Marković V, Glavina G, Eterović D, Punda A, Brdar D. Dual ectopic thyroid gland: sonography and scintigraphy of lingual and sublingual thyroid. Clin Nucl Med 2014;39:5568.

9. Jain TK, Meena RS, Bhatia A, Sood A, Bhattacharya A, Mittal BR. Dual thyroid ectopia-role of thyroid scintigraphy and neck ultrasonography. Indian J Nucl Med 2015;30:33840.

10. Nakamura S, Masuda T, Ishimori M. Dual ectopic thyroid associated with thyroid hemiagenesis. Endocrinol Diabetes Metab Case Rep 2018;2018:18-0026.

11. Castanet M, Polak M, Bonaiti-Pellié C, Lyonnet S, Czernichow P, Léger J, et al. Nineteen years of national screening for congenital hypothyroidism: familial cases with thyroid dysgenesis suggest the involvement of genetic factors. J Clin Endocrinol Metab 2001;86:2009-14.

12. Karakoc E, Turan S, Akpinar I, Isguven P, Adal E, Haklar $\mathrm{G}$, et al. Screening of parents and siblings of patients with thyroid dysgenesis by thyroid function tests and ultrasound. Horm Res 2008;70:329-39.

13. Borges MF, Sedassari NA, Sedassari AA, Souza LRMF, Ferreira BP, Lara BHJ, et al. Timing of thyroid ultrasonography in the etiological investigation of congenital hypothyroidism. Arch Endocrinol Metab 2017;61:432-7.

14. Yeung VT, Loong EP, Cockram CS. Cretinism and lingual 
thyroid presenting in an adult. Postgrad Med J 1987;63:8813.

15. Toso A, Colombani F, Averono G, Aluffi P, Pia F. Lingual thyroid causing dysphagia and dyspnoea. Case reports and review of the literature. Acta Otorhinolaryngol Ital 2009;29:213-7.

16. Adelchi C, Mara P, Melissa L, De Stefano A, Cesare M. Ectopic thyroid tissue in the head and neck: a case series. BMC Res Notes 2014;7:790.

17. Chanoine JP, Toppet V, Lagasse R, Spehl M, Delange F. Determination of thyroid volume by ultrasound from the neonatal period to late adolescence. Eur J Pediatr 1991;150:395-9.

18. Perry RJ, Hollman AS, Wood AM, Donaldson MDC. Ultrasound of the thyroid gland in the newborn: normative data. Arch Dis Child Fetal Neonatal Ed 2002;87:F209-11.

19. Aydıner Ö, Aydıner EK, Akpınar I, Turan S, Bereket A. Normative data of thyroid volume-ultrasonographic evaluation of 422 subjects aged $0-55$ years. J Clin Res Pediatr Endocrinol 2015;7:98-101.

20. De Bruyn R, Ng WK, Taylor J, Campbell F, Mitton SG, Dicks-Mireaux C, et al. Neonatal hypothyroidism: comparison of radioisotope and ultrasound imaging in 54 cases. Acta Paediatr Scand 1990;79:1194-8.
21. Takashima S, Nomura N, Tanaka H, Itoh Y, Miki K, Harada T. Congenital hypothyroidism: assessment with ultrasound. Am J Neuroradiol 1995;16:1117-23.

22. Perry RJ, Maroo S, Maclennan AC, Jones JH, Donaldson MD. Combined ultrasound and isotope scanning is more informative in the diagnosis of congenital hypothyroidism than single scanning. Arch Dis Child 2006;91:972-6.

23. Ruchala M, Szczepanek E, Sowiński J. Diagnostic value of radionuclide scanning and ultrasonography in thyroid developmental anomaly imaging. Nucl Med Rev 2011;14:21-8.

24. Kreisner E, Camargo-Neto E, Maia CR, Gross JL. Accuracy of ultrasonography to establish the diagnosis and aetiology of permanent primary congenital hypothyroidism. Clin Endocrinol (Oxf) 2003;59:361-5.

25. Sood A, Kumar R. The ectopic thyroid gland and the role of nuclear medicine techniques in its diagnosis and management. Hell J Nucl Med 2008;1 1:168-71.

26. Bubuteishvili L, Garel C, Czernichow P, Léger J. Thyroid abnormalities by ultrasonography in neonates with congenital hypothyroidism. J Pediatr 2003;143:759-64.

27. Karakoc-Aydiner E, Turan S, Akpinar I, Dede F, Isguven P, Adal E, et al. Pitfalls in the diagnosis of thyroid dysgenesis by thyroid ultrasonography and scintigraphy. Eur J Endocrinol 2012;166:43-8. 